\title{
4. Magnetic Field Survey with the Aid of Polar Patrol Balloons in Antarctica
}

\author{
By Ryoichi FujII, ${ }^{*)}$ Hiromitsu AKIYAMa, $\left.{ }^{* *}\right)$ Susumu KoKUbun, ${ }^{* * *)}$ \\ Nobuyuki YaJIma, ${ }^{* *}$ Jyun NishimURA, ${ }^{* *}$ and Takeo HiraSAWA* \\ (Communicated by Takesi Nagata, M. J.A., March 12, 1991)
}

\begin{abstract}
A Polar Patrol Balloon (PPB) accomplished a complete circumpolar flight over the Antarctic. The total intensity of the geomagnetic main field measured by an onboard magnetometer shows a satisfactory agreement with that calculate from IGRFmodel. A coincidence of the actual PPB trajectory with that calculated from the wind data indicates that the wind flow with the synoptic scale has little variability in the summer stratosphere in Antarctica. The novel PPB systems open new fields for the detailed observations of polar phenomena at a balloon altitude.
\end{abstract}

Key words: Antarctica; magnetic survey; balloon.

Introduction. The Polar Patrol Balloon (hereinafter referred to as PPB) project is a long duration circumpolar balloon experiment in Antarctica. Since 1984, the National Institute of Polar Research (NIPR) and the Institute of Space and Astronautical Science (ISAS) have developed ballooning technologies for the PPB program. ${ }^{1,2)}$ In 1987 and 1990 three test flights were carried out at Syowa Station $\left(69.0^{\circ} \mathrm{S}, 39.6^{\circ} \mathrm{E}\right)$, Antarctica. ${ }^{3), 4)}$ These flights aimed at observing the atmospheric and radiation environment in the Antarctic stratosphere and testing PPB instruments. At the last experiment in January 1990, a PPB almost completed a circumpolar flight (about 7/8 of the circle) and followed the predicted trajectory that had been calculated with statistical wind profiles in the Antarctic stratosphere. These experiments have convinced us that PPB would return to the launching area with a strong possibility. Having a success of the test flights of the PPB, the first actual experiment for scientific observations was carried out in December 1990January 1991 with a successful complete circumpolar flight around the Antarctic.

Concept and feasibility studies of the PPB. The most important point in the concept of PPB is that we utilize the advantage that there are no sunsets during summer season in Antarctica. In this season the long duration flight over a few weeks is possible using a zero-pressure balloon with an auto-ballast control, which is consuming relatively small amounts of ballasts. ${ }^{1,2)}$ By investigating the radiation environment over Antarctica in summer, we estimate that the ballast consumption is at most 1 to $2 \%$ of the total PPB weight per day to keep the level of a balloon. This enables the level flight of PPB over 3 weeks or more (Fig. 1).

We have three data logging and telemetry systems on board the PPB, multi-IDs ARGOS, a data recorder and a real time telemetry system (Fig. 1). One unique feature of the PPB system is a multi-ID ARGOS system. The normal ARGOS system is operated usually with a small data transmission rate of 32 Byte $(256 \mathrm{bit}) / 100-200 \mathrm{sec}$. We are allowed

*) National Institute of Polar Research, Kaga 1-9-10, Itabashi, Tokyo 173, Japan.

**) Institute of Space and Astronautical Science, Yoshinodai 3-1-1, Sagamihara, Kanagawa 229, Japan.

***) Geophysics Research Laboratory, University of Tokyo, Hongo 7-3-1, Bunkyo, Tokyo 113, Japan. 


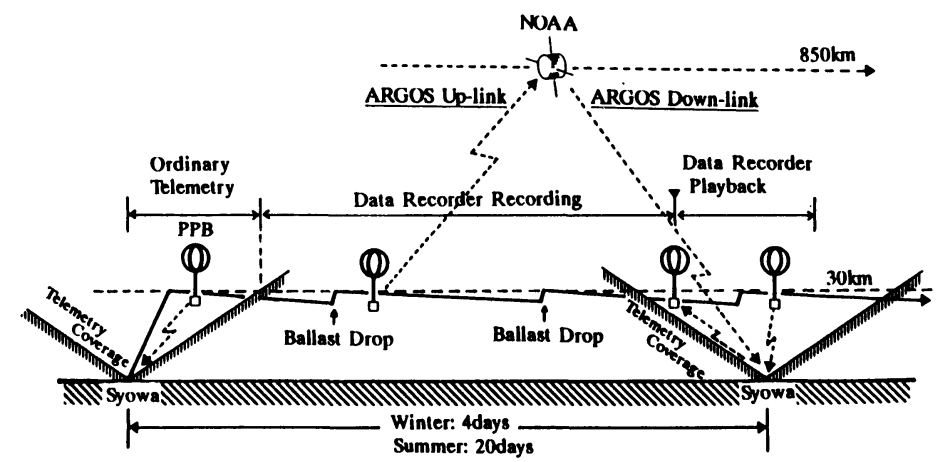

Fig. 1. Schematic illustration of the auto-ballast control and the data telemetry systems of PPBs.

fortunately from the Service ARGOS to use multi-IDs for one transmitter, actually 21 IDs for the PPB. The multi-ID ARGOS enables us to send continuously 30 sec sampling data to the ground throughout the PPB flight. The real-time telemetry is possible only when the PPB is located within the telemetry coverage range from the launching cite (Syowa Station). Data in the onboard data recorder, which has the largest data storage, can be transmitted to the ground when the PPB returns to the vicinity of Syowa.

Yamanaka et al. ${ }^{5)}$ investigated the details of Antarctic large-scale wind patterns by using wind profile data in the stratosphere, and they concluded that the most appropriate times for long-term circumpolar flights are December and January at a level above $30 \mathrm{~km}$. During these periods the mean duration to complete the circumpoler flight is calculated to be three to four weeks. The maximum north-south deviation at the time of the PPB return due to the global-scale waves are estimated less than $7^{\circ}$ in latitude that is within a detectable range through telemetry from the PPB.

PPB flight in December 1990-January 1991. A PPB flight experiment was carried out to observe magnetic field and to check other instruments developed for the PPB in December 1990-January 1991. The balloon had an ARGOS positioning/data transfer system, data recorder, telemetry and command receiver. Several parameters of the PPB experiment are listed in Table I. Fig. 2 shows the trajectory of the PPB flight. The PPB was launched on December 25 from Syowa Station and drifted westward. The initial ceiling height was $30 \mathrm{~km}$ and the auto-ballast was set to $27 \mathrm{~km}$. On December 26 the PPB started to drop the ballasts. During December 26-31 the ballast consumption was about $1 \%$ of the total weight of PPB per day. However, after January 1, 1991 the consumption increased to about $5 \%$ because of the effect of the sunset on the ground below the balloon location. These consumption were almost the same amount what we had expected. On January 9,

Table I. Parameters of the PPB which was launched in December 1990-January 1991 from Syowa Station, Antarctica

\begin{tabular}{l|cc|c|c|c|c|c}
\hline & Launching date & $\begin{array}{c}\text { Balloon } \\
\text { size }\end{array}$ & $\begin{array}{c}\text { Payload } \\
\text { weight }\end{array}$ & Ballast & $\begin{array}{c}\text { Ceiling } \\
\text { altitude }\end{array}$ & Observation \\
\hline PPB & $08: 25$ UT & Dec. 25,1990 & $25,000 \mathrm{~m}^{3}$ & $116 \mathrm{~kg}$ & $152 \mathrm{~kg}$ & $30 \mathrm{~km}$ & $\begin{array}{l}\text { air temperature } \\
\text { and pressure } \\
\text { magnetic field }\end{array}$ \\
\hline
\end{tabular}




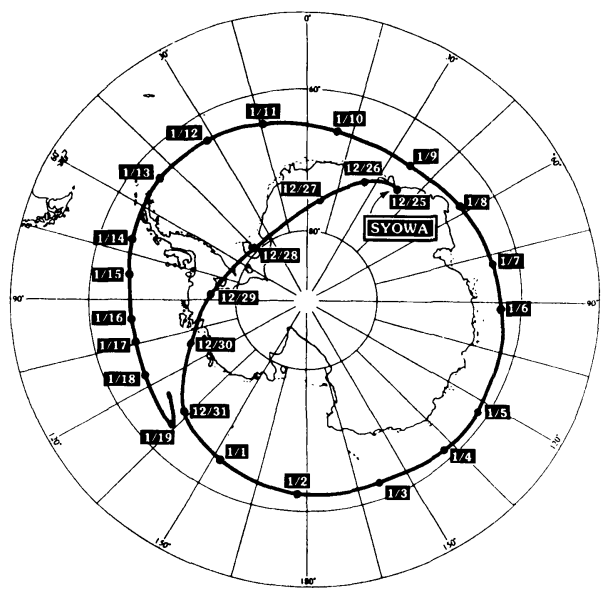

Fig. 2. The trajectory of PPB which was launched from Syowa Station on December 25, 1990.

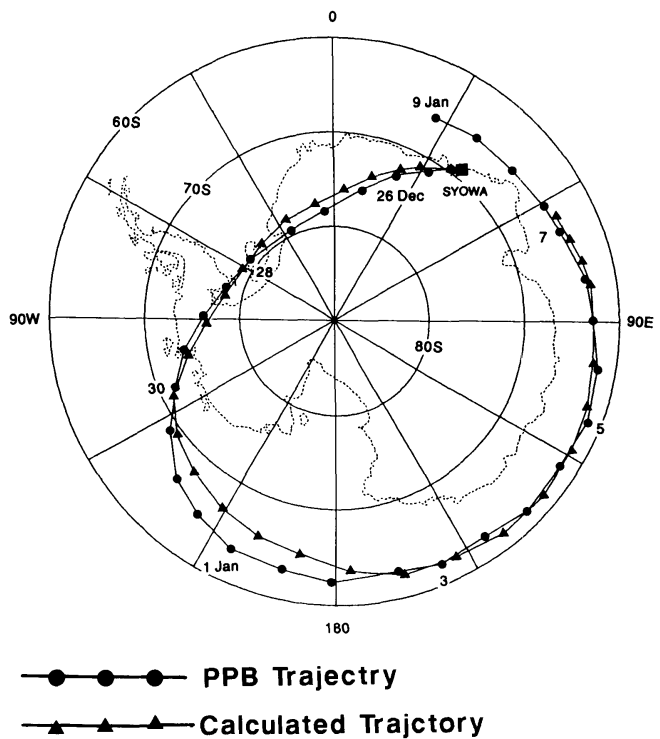

Fig. 3. Actual PPB trajectory along with that calculated from the wind data at the height of $15 \mathrm{mb}(\sim 30 \mathrm{~km})$.

the PPB passed the $39.6^{\circ} \mathrm{E}$ line (longitude of Syowa Station) at about $400 \mathrm{~km}$ north of Syowa. The PPB came back to the launching area and accomplished a complete circumpolar flight over the Antarctic.

Trajectory of PPB. Fig. 3 shows a satisfactory coincidence of the actual PPB trajectory with that calculated from the wind data at the height of $15 \mathrm{mb}(\sim 30 \mathrm{~km})$, which are obtained by the objective analysis of the Japan Meteorological Agency (JMA). ${ }^{6}$ The time and horizontal resolutions of the JMA analysis are 12 hours (00 UT, 12 UT) and 1.875 degrees for both latitude and longitude, respectively. The difference between the two trajectories is small especially in latitude. This confirms that the wind flow with the 
synoptic scale (the order of $1000 \mathrm{~km}$ or more) has little variability in the summer stratosphere in Antarctica, as has been anticipated on the basis of the observational and theoretical studies. ${ }^{5), 7)}$ The close agreement between observed and calculated trajectories indicates also that the JMA analysis is highly reliable for expressing the actual condition of the wind flows with the synoptic scale in the Antarctic stratosphere. The difference (at most $\sim 2$ degrees in latitude), which is observed in the area of $120^{\circ} \sim 180^{\circ} \mathrm{W}$ longitude in Fig. 3, is considered to originate from the variability of wind flows in the stratosphere with the scale smaller than synoptic one. Further analyses of this type using the PPB trajectory data with fine time resolution will are desirable to discuss this problem in more detail.

Magnetic field survey by PPB. By a proton magnetometer on board PPB, the total intensity (F) of the geomagnetic main field was measured at a height of about $30 \mathrm{~km}$ over the Antarctic. The specification of the magnetometer are: measurable range 40,000 73,000 nT, accuracy $1 \mathrm{nT}$, sampling period $32 \mathrm{sec}$ and output format 16 bits. Fig. 4 shows observed total intensity during the PPB flight in the period from 26 December 1990 (one day after the PPB launching from Syowa) to 9 January 1991 when PPB completed a circumpolar flight and came back to Syowa, along with the total intensity IGRF (International Geomagnetic Reference Field)-1990 calculated with the coefficients of IGRF-1985 and the secular variation model for 1985-1990. Fig. 4 shows a satisfactory agreement in the total intensity of the geomagnetic field between the observed and IGRF-model through the PPB flight, and the difference is usually much less than $1 \%$. The PPB passed over the southern magnetic pole on January 3-4, 1991. We shows in Fig. 5 the observed total intensity ( $\mathrm{Fo}$ ), the calculated IGRF-1990 ( $\mathrm{Fc}$ ) and the difference $\Delta \mathrm{F}=\mathrm{F}_{0}-\mathrm{Fc}$ in the vicinity of the magnetic pole; the difference $\Delta \mathrm{F}$ is plotted here with an enlarge scale indicated in the right-side coordinate of Fig. 5. The geomagnetic activity during the PPB flight was rather quiet (the maximum Kp value on January 3-4 was 3), so that the observed $\Delta \mathrm{F}$ over the southern magnetic pole area seems to be attributable mainly to local magnetic anomalies originated from the earth's crust. The IGRF Model will be revised at the IUGG/IAGA Assembly in Vienna in August 1991. This revision will be based on adoption of the definitive main field-model for the epoch 1985, adoption of a new main-field model (non-definitive) for 1990 with a predictive model for the secular geomagnetic variation for the interval 1990-1995, after comparing candidate models proposed for the new IGRF. The data obtained by PPB experiment will contribute to the evaluation of the various proposed models because the magnetic survey data in Antarctica are very sparse, in particular around the southern magnetic pole.

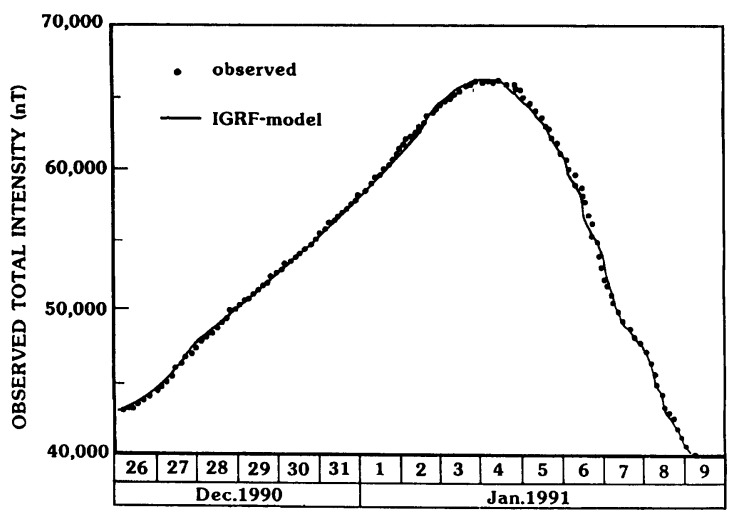

Fig. 4. The observed total intensity of the geomagnetic field during the PPB flight and the total intensity of IGRF-1990. 


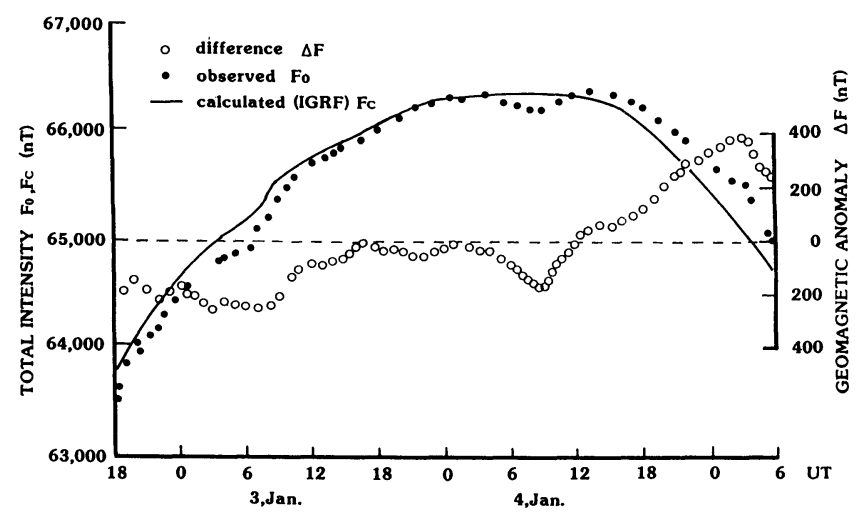

Fig. 5. The observed total intensity (Fo), the calculated IGRF-1990 $(\mathrm{Fc})$ and the difference $\Delta \mathrm{F}=\mathrm{Fo}_{0}-\mathrm{Fc}$ in the vicinity of the magnetic pole.

In summary, the success of a long duration circumpolar flight of novel PPB systems enable us to open new fields for the detailed observations of polar phenomena at a balloon altitude, such as electric field, magnetic field, auroral x-rays, ozones and NOx. Besides these observations, because of the long duration flights more than a few weeks, PPB would become the useful systems for further studies of rare occurrence events of astronomical interests such as isotope separation of cosmic rays, gamma ray bursts, low energy anti-particles in cosmic rays. We plan to launch three or four PPBs successively to establish a moving station network at a balloon altitude for a long interval (about three weeks) over the Antarctic region for geophysical, space and astronomical observations. This PPB project has been done under the PPB Working Group (N. Yajima: Chairman). The authors are very grateful to the members of the Working Group and the 32nd Japanese Antarctic Research Expedition members for the PPB experiments at Syowa. The authors also express their gratitude to Drs. M.D. Yamanaka, H. Kanzawa, K. Yamazaki and F. Toyama for their kind helps in the data analysis.

\section{References}

1) Nagata, T. et al. (1985): Mem. Nat'l Inst. Polar Res., Spec. Issue, 38, 156-163.

2) Nishimura, J. et al. (1985): Adv. Space Res., 5, 87-90.

3) Miyaoka, H., Mukai, H., and Saito, H. (1988): Report of the 28th Japanese Antarctic Research Expedition 1986-1988 (ed. Nat'l Inst Polar Res.). pp. 165-174.

4) Kadokura, A. (1990): Report of the 30th Japanese Antarctic Reseach Expedition 1988-1990 (ed. Nat'l Inst Polar Res.). pp. 165-178.

5) Yamanaka, M. D., Yamazaki, H., and Kanazawa, H. (1988): Proc. NIPR Symp. Upper Atmos. Phys., 1, 65-74.

6) Japan Meteorological Agency. (1990): Outline of Operational Numerical Weather Prediction, Appendix to Progress Report on Numerical Weather Prediction (WMO/TOno. 352$)$, p. 125 .

7) Yamazaki, K. (1987): Proc. NIPR Symp. Polar Meteorol. Glaciol., 1, 39-53. 